and there are few longitudinal studies that have used a comprehensive neuropsychological test battery. Aim of study was to look at how young adults born SGA perform on a variety of neuropsychological tests, and to see whether they have problems of specific or general origin.

Methods Population-based follow-up study at age 19 of 59 termborn SGA (birth weight $<10$ th centile, mean: $2915 \mathrm{~g}$ ) and 81 controls (birth weight $>10$ th centile, mean: $3707 \mathrm{~g}$ ). One participant in the SGA group had cerebral palsy and was excluded from analysis.

A standardized neuropsychological test battery was used to assess several functions: memory, language, attention, executive functions and visual-motor integration.

Results The SGA-group performed significantly poorer than controls $(p<0.01)$ on several tests. These were tests assessing memory; (Wechsler memory scale-III: auditive immediate memory and mental control), attention (Trail making test), executive functions (Design fluency) and visual-motor-integration (Motor coordination test). The groups did not differ in visual memory tasks, long term memory, language functions and several other attention/executive tasks.

Conclusions Our results suggest that young adults born SGA have specific neuropsychological difficulties, especially problems with auditive learning, eye-hand-coordination, and they are slower at performing and initiating tasks compared to controls. This might further indicate that children born SGA can be in need of special education in school.

\section{USING THE AGES AND STAGES QUESTIONNAIRE TO CAPTURE PATTERNS OF RISK FOR DEVELOPMENTAL DELAY IN CANADIAN CHILDREN BORN LATE PRETERM}

doi:10.1136/archdischild-2012-302724.0241

${ }^{1.2} \mathrm{~K}$ Benzies, ${ }^{3} \mathrm{~J}$ Magill-Evans, ' $\mathrm{J}$ Kurilova, ${ }^{4} \mathrm{M}$ Ballantyne. 'Nursing; ' 2 Department of Pediatrics, University of Calgary, Calgary; ${ }^{3}$ Department of Occupational Therapy, University of Alberta, Edmonton, $A B ;{ }^{4}$ Nursing, McMaster University, Hamilton, ON, Canada

Background and aims Nearly three quarters of preterm infants are 34 to 36 weeks gestational age (GA), or late preterm (LPT). LPT children are at significantly greater risk for neurological, language and communication delays, social and emotional problems, and attention-deficit/hyperactivity disorder than children born full term. Developmental screening and early intervention may mitigate these risks. Little is known about early patterns of risk across developmental domains in the LPT group as this grouping has been consistently defined only recently. The purpose of this study was to describe patterns of development in Canadian children born LPT.

Methods Mothers of 61 LPT infants (57\% male) completed the Ages and Stages Questionnaire $3^{\text {rd }}$ edition (ASQ-3) when their child was 4, 8 and 18 months corrected age. The 30-item ASQ-3 addresses communication, gross motor, fine motor, problem solving, and personal social functioning. Referral cut-off is $<2 \mathrm{SD}$ below the mean, and monitoring is required between 1 and 2 SD below.

Results There was a clear inverse relationship between GA and proportion of children requiring referral or monitoring over time. For 34 weeks GA, $67 \%$ to $83 \%$ of children demonstrated risk in one or more domains; for 35 weeks, the proportion was $50 \%$ to $65 \%$; and still lower for 36 weeks (40\% to 54\%). Communication and gross motor were the most problematic domains.

Conclusion The ASQ-3 may be useful to capture delays in LPT children, particularly in communication and gross motor domains. These results have implications for early childhood developmental assessment and intervention services.

\section{SCREENING ASSESSMENT OF PSYCHOMOTOR DEVELOPMENT OF PRESCHOOL CHILDREN IN VLORA- ALBANIA. A CROSS-SECTIONAL STUDY DURING JULY 2011-FEBRUARY 2012}

doi:10.1136/archdischild-2012-302724.0242
A Saliaj. Mother \& Child Care Department, Faculty of Public Health, University of VIora, Vlora, Albania

Background The assessment of psychometric parameters is an important part of growth\&development evaluation of preschool children. The contributing factors of psychomotor functions are parents' Socio-Economic Status (SES), mother(teacher)/child interaction and environmental quality play. It's important to evaluate the weak points of this particularly neglected aspect of child development in Vlora-Albania.

Aim Assessment of the most problematic areas of psychomotor development of children in Vlora-Albania and distribution of psychometric parameters according to the quality of care\&learning environment and to SES of children's parents.

Methods This cross-sectional study included all the 75 preschoolers enrolled in two kindergartens and the institutionalized children in Foster-Care, Vlora-Albania. The evaluation of psychomotor development was done based on the standard international test of Age\&Stage Questionnaires-3, referring to children chronological age. Evaluation of child care \& learning environment was done according to ECERS-R (Early-Care-Environment-Rate-Scale). Socioeconomic status distribution was based on father's occupation and classified on European Socio-Economic Classification (E-SEC).

Abstract 242 Table 1 The psycho-motor development according to ECERS-R

\begin{tabular}{llll}
\hline $\begin{array}{l}\text { Daycares Centres of Vlora-Albania, } \\
\text { included in the research }\end{array}$ & $\begin{array}{l}\text { Private } \\
\text { kindergarten } \\
\text { AULONA }\end{array}$ & $\begin{array}{l}\text { Public } \\
\text { kindergarten } \\
\text { Nr.10 }\end{array}$ & $\begin{array}{l}\text { Foster Care } \\
\text { of Vlora }\end{array}$ \\
\hline $\begin{array}{l}\text { Scoring Rate of ECERS-R } \\
\text { Percentage of children with at least one }\end{array}$ & 5.3 (above good) & 4.1 (above minimal) & $\begin{array}{l}2.9 \text { (under } \\
\text { minimal) } \\
\text { problematic sector }\end{array}$ \\
\hline
\end{tabular}

Results In this study we found that $57 \%$ of 63 kindergarten preschoolers had at least one problematic psychometric parameter and all the ones in Foster-Care had at least one also. The most problematic item at the kindergarten preschoolers was Personal-Social sector, and at the Foster-Care children was Communication. The highest percentage $(75 \%)$ of delays of psychometric parameters was found at children whose fathers' SES belong to class VII (semiroutine occupations)

Conclusions A significant number of preschoolers and all institutionalized children at Vlora-Albania have abnormal psychometric parameters. A better quality of care\&play environment leads to less delays at psychomotor development.

\section{SENSORY PROCESSING OF CHILDREN WITH AUTISM: UNITING EVIDENCE AND PRACTICE}

doi:10.1136/archdischild-2012-302724.0243

${ }^{1} \mathrm{HF}$ Ayyash, ${ }^{2} \mathrm{E}$ Barrett, ${ }^{3} \mathrm{M}$ Ogundele. 'Department of Paediatrics; ${ }^{2}$ Paediatric Occupational Therapy Department, Doncaster Royal Infirmary, Doncaster; ${ }^{3}$ Department of Community Paediatrics, Alder Hey Children's Hospital, Liverpool, UK

Background Sensory processing function is the child's ability to register, modulate and discriminate between different sensory information arising from the body (e.g. tactile and vestibular sense) and those received from the environment (vision, auditory and gustatory senses). Individuals with autism commonly experience sensory processing difficulties, which can impact upon functional performance in activities of daily living.

Aim To investigate the sensory processing patterns of children with autism

Methods 15 children aged between 4 to 10 years old (Average 6.9 years) who were diagnosed with autism were included in the study. 
Their parents/carers completed the Sensory Profile Caregiver's Questionnaire. This is a standardised tool designed to assess children's sensory processing dysfunction in their daily functional performance.

Results There were 13 boys and 2 girls. Nine children were attending mainstream schools and six attended special schools. The assessments completed highlighted that all children experienced some form of sensory processing difficulty (Figure 1).

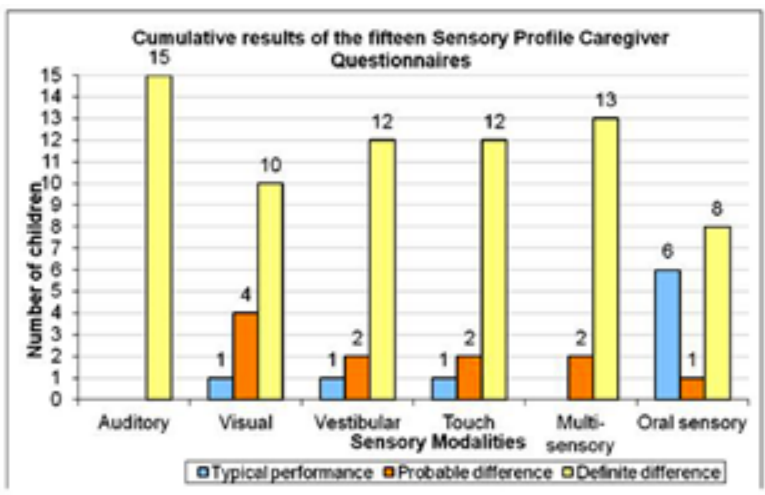

\section{Abstract 243 Figure 1}

Conclusion The findings support the key theme found in literature indicating that individuals with autism commonly experience sensory processing difficulties. There seem to be clear links between sensory processing difficulties and reduced functional performance during school and home activities. Further controlled studies on sensory processing in children with autism are recommended.

\section{CHILD GENDER AND BIRTH ORDER INFLUENCE OUTCOMES OF AN EARLY INTERVENTION PROGRAM AT AGE 7 YEARS}

doi:10.1136/archdischild-2012-302724.0244

${ }^{1,2} \mathrm{~S}$ Tough, ${ }^{3} \mathrm{R}$ Mychasiuk, ${ }^{1,3} \mathrm{KM}$ Benzies. 'Department of Paediatrics; ${ }^{2}$ Department of Community Health Sciences, ${ }^{3}$ Faculty of Nursing, University of Calgary, Calgary, AB, Canada

Background and aim Early intervention programs are critical to optimize development for children in low-income families. Principles of social justice and inclusion increase the tendency to employ similar early intervention approaches for all program children. This approach fails to maximize intervention outcomes, and may benefit certain sub-groups of children more than others. The purpose of this study was to explore differences in receptive language scores in children who participated in a two-generation preschool program while controlling for child characteristics.

Method The program included centre-based care, parenting education, and family support. We assessed 62 children using the Peabody Picture Vocabulary Test III (PPVT-III) at program entry and exit, and age 7 years.

Results Repeated measures ANOVA's using child characteristics as covariates, revealed gender differences in receptive language scores at age 7 years favoring males, $F(1,61)=3.71, p=0.06$. Children with an older sibling exhibited significantly better receptive language scores, $F(1.61)=4.38, p=0.04$. Ethnicity, English as a first language, time in program, and family income were unrelated to receptive language scores, $p$ 's $>0.10$.

Conclusions The finding that males outperformed females is surprising because females tend to have stronger language skills than age-matched males. Younger siblings may have benefited from increased exposure to older siblings who had participated previously in the program. Results suggest that early intervention programs for children living in low-income families may benefit from alterations to program curricula that promote sex-differentiated learning strategies and focus on family dynamics.

\section{SPECTRUMS AND FREQUENCIES OF SLC26A4 AND SLC26A5 GENES MUTATION AMONG PATIENTS WITH INHERITED HEARING LOSS FROM DIFFERENT REGIONS OF RUSSIA}

doi:10.1136/archdischild-2012-302724.0245

L Dzhemileva, S Lobov, E Khusnutdinova. Human Molecular Genetics, Institute of Biochemistry and Genetics, Ufa Research Center, Russian Academy of Sciences, Ufa, Russia

Background The molecular etiology of hearing impairment in Russia has not been fully investigated. Study of GJB2, GJÂ6, GJB3, 12SrRNA, $t R N A^{\operatorname{Ser}(U C N)}$ and $M Y O 7 A$ genes revealed that $55 \%$ of the patients with hearing loss carried GJB2 mutations in different regions of Russia. The SLC26A4 and SLC26A5 genes mutations are analyzed in this study.

Methods Two hundred and fifty unrelated deaf patients were included. The all coding exons of SLC26A4 and first ten exons of SLC26A5 genes were sequenced in all 250 patients, including 130 patients carrying bi- and mono-allelic recessive GJB2 mutations, two patients carrying a known GJB2 dominant mutation c.224G>A (p.Arg75Gln), as well as six patients with $m t D N A$ (m.1555A>G, m.961ins $\mathrm{C}_{(\mathrm{n})}, \mathrm{m} .961$ delTinsC $\mathrm{C}_{(\mathrm{n})}$ and $\left.\mathrm{m} .7444 \mathrm{G}>\mathrm{A}\right)$ mutations.

Results Eight patients $(3.2 \%, 8 / 250)$ with non-syndromic hearing loss were found carrying SLC26A4 and SLC26A5 mutation and polymorphic variants. Among them, one patient with bi-allelic SLC26A4 mutations (c.85G>C (p.Glu29Gln) and c.149T>C (p.Leu50Arg)) had EVA by CT scan. One patient with nonsyndromic hearing loss was heterozygous for mutations c.919$2 \mathrm{~A}>\mathrm{G}$ in SLC26A4 gene. The most common SLC26A5 gene mutation, g. $-53-2 \mathrm{~A}>\mathrm{G}$, accounted for $0.4 \%(1 / 250)$ of all SLC26A4 mutant alleles. Two patients with non-syndromic hearing loss were heterozygous for polymorphic variant c.49548A>G (p.Gly740Ser) in SLC26A4, and one was heterozygous for polymorphic variant g.38190T>C in SLC26A5. The novel SLC26A4 gene mutation g.29607delA was identified in one patient with EVA.

Conclusion Our results suggest that GJB2, SLC26A4 and SLC26A5 mutations together make up a major cause of congenital hearing loss in the different populations from Russia.

\section{MATERNAL UPD2: A NEW GENETIC LOCUS FOR RUSSELL- SILVER SYNDROME}

doi:10.1136/archdischild-2012-302724.0246

${ }^{1} \mathrm{MJ}$ Dasouki, ${ }^{2} \mathrm{X}$ Tan, ${ }^{3} \mathrm{~A}$ Patel, ${ }^{2} \mathrm{MG}$ Butler, Genetics. ${ }^{1}$ Departments of Pediatrics 8 Medicine; '2Department of Psychiatry, University of Kansas Medical Center, Kansas City, KS: ${ }^{3}$ Department of Molecular and Human Genetics, Baylor College of Medicine, Baylor University, Houston, TX, USA

Background and aims Russell-Silver syndrome (RSS) is a genetically heterogeneous and phenotypically recognizable disorder characterized by IUGR followed by postnatal growth deficiency with head sparing, trigonocephaly, limb-length asymmetry, variable hypoglycemia, and learning disabilities. Hypomethylation of the paternal imprinting center 1 (IC1) of chromosome 11p15.5 and maternal UPD7 are identified in $35 \%-50 \%$ and $10 \%$ of affected individuals respectively.

Methods We studied the gDNA of a 16 month old Caucasian girl with growth failure and facial features consistent with RSS using Chromosomal Microarray Analysis (CMA) and DNA microsatellite genotyping.

Results Oligonucleotide-based CMA showed no copy number abnormality while SNP-array based CMA showed segmental Long Continuous Stretches of Homozygosity (LCSH) of $64 \mathrm{Mb}$ in size involving chromosome 2 [2q11.1q13 (17.66 Mb), 2q22.1q31.1 (28.67 $\mathrm{Mb}$ ) and $2 \mathrm{q} 36.2 \mathrm{q} 37.3(17.69 \mathrm{Mb})]$. DNA microsatellite analysis showed maternal isodisomy $2 q$ of these regions. TIGD1 and MYEOV2 map to 2 q37.1 and 2q37.3 and are predicted to be paternally expressed. However, causative imprinting of either gene was excluded since both genes map outside the smallest region of overlap between our patient and two unrelated patients with features of RSS reported by Bruno et al (J Med Genet, 2011) showing LCSH at 2q. 